\author{
S.P. Sridhar ${ }^{1}$, S. Arun Kumar ${ }^{2}$, P. Sathiya ${ }^{1 *}$ \\ ${ }^{1}$ Department of Production Engineering, National Institute of Technology. Tiruchirappalli- \\ 620015, Tamilnadu, India \\ ${ }^{2}$ School of mechanical engineering, SASTRA University, Thanjavur-613401, Tamilnadu, India \\ *psathiya@nitt.edu
}

\title{
A STUDY ON THE EFFECT OF DIFFERENT ACTIVATING FLUX ON A-TIG WELDING PROCESS OF INCOLOY 800H
}

\begin{abstract}
This study investigates the effect of different activating flux such as $\mathrm{V}_{2} \mathrm{O}_{5}, \mathrm{TiO}_{2}, \mathrm{MoO}_{3}, \mathrm{Cr}_{2} \mathrm{O}_{3}$, and $\mathrm{Al}_{2} \mathrm{O}_{3}$ on $\mathrm{A}$ TIG welding process of Incoloy $800 \mathrm{H}$. The influence of the flux on the depth of penetration and on mechanical and metallurgical characteristics of the weld were studied and compared with autogeneous TIG welds which were welded with the same process parameters and conditions. The use of $\mathrm{TiO}_{2}$ flux gave full depth of penetration and the use of $\mathrm{V}_{2} \mathrm{O}_{5}, \mathrm{Cr}_{2} \mathrm{O}_{3}$ flux gave increased penetration as compared to autogeneous TIG welds while the use of $\mathrm{Al}_{2} \mathrm{O}_{3}$ and $\mathrm{MoO}_{3}$ led to the detoriation of the effect.
\end{abstract}

Key words: A-TIG, Incoloy 800H, Activating Flux, Carbide, Corrosion

\section{INTRODUCTION}

Incoloy $800 \mathrm{H}$ (UNS N08810), which comes under the group of austenitic nickel-iron chromium steel, exhibits resistance to the carburization, corrosion and oxidation at high temperature. The combination of appreciable strength and corrosion resistance in a series of elevated temperature makes this alloy useful in many applications such as cracker tubes in petrochemical furnace, headers and pigtails, fourth generation nuclear power plant components, equipment and furnace components etc. [1]. GTAW process is preferred for producing high quality weld joint where control of weld bead and shape is possible ensuring the metallurgical stability of the welded joints. On the other hand the major disadvantages of TIG welding process are the low productivity due to the number of passes required when welding thick sections and the requirement of highly skilled welders. To overcome these disadvantages, A-TIG welding process, a variant of TIG welding process, was developed by Paton Electric Welding Institute (1960). In this process a thin layer of fluxes (oxide, halide, fluoride and chloride) was applied on the region where the weld was to be made. The activating flux improved the depth of penetration up to $300 \%$ as compared to autogeneous TIG welding [2]. The reversed Marangoni convection and the arc constriction effect were considered as the two major mechanisms for the increased depth of penetration in A-TIG welding process [3]. But research is still going on to find the exact mechanism which causes 
the depth of penetration. A-TIG welding process was carried out in Nimonic 263 alloy with three fluxes and the results suggested that as the thickness of the flux coating increased, the depth of penetration decreased. The fluxes did not decompose fully and this affected the viscosity of the molten metal flow and hence resulted in lower depth of penetration [4]. ATIG welding was done on stainless steel $(0 \mathrm{Cr} 18 \mathrm{Ni}$ ) $)$ with two different activating fluxes $\mathrm{SiO}_{2}$ and $\mathrm{TiO}_{2}$. The increased depth of penetration using $\mathrm{SiO}_{2}$ flux was due to arc constriction effect and reversed Marangoni convection whereas the increase in depth of penetration by using $\mathrm{TiO}_{2}$ flux was only due to reversed Marangoni convection [5]. Sakthivel et al. compared the creep strength of TIG \& A-TIG welded austenitic 316LN steel and concluded that the A-TIG weldments had lower creep rupture life than the TIG weldments because the TIG welded joints had lower weld strength reduction factor as compared to the A-TIG joints [6]. Devendranath Ramkumar et al. performed A-TIG welding on 904L super austenitic stainless steel with the use of $85 \% \mathrm{SiO}_{2}+15 \% \mathrm{TiO}_{2}$ and reported that the weld penetration increased three times as compared to the autogeneous TIG weld. A-TIG weldments failed in the weld zone in tensile testing due to the lower hardness in the weld region as compared to the base material and HAZ [7]. Monoj Kumar et al. investigated the tensile properties of ATIG in Inconel 718 joints welded using $\mathrm{SiO}_{2}$ \& $\mathrm{TiO}_{2}$ flux. The $\mathrm{TiO}_{2}$ A-TIG weldments had higher tensile strength as compared to $\mathrm{SiO}_{2}$ weldments and also the A-TIG joints had higher strength than that of the parent material [8]. Shyu et al. reported that the increased $\delta$ ferrite content in the weld zone of A-TIG welded austenitic stainless steel improved the mechanical properties such as ductility, hardness and strength than the TIG welded joints [9]. The combination of $50 \% \mathrm{SiO}_{2}+50 \% \mathrm{MoO}_{3}$ and $\mathrm{SiO}_{2}$ flux reduced the hot cracking susceptibility on Inconel 718 weldments and the higher depth to width ratio was obtained using $50 \% \mathrm{SiO}_{2}+$ $50 \% \mathrm{MoO}_{3}$ and $50 \% \mathrm{SiO}_{2}+50 \% \mathrm{NiO}$ flux combination [10]. Sairam et al. performed dissimilar welding of Incoloy $800 \mathrm{H}$ and austenitic stainless steel (321) by using two different filler material, Inconel 617 and Inconel 82 [11]. In this work an attempt is made to find the effect of different activating flux on A-TIG welding process of Incoloy $800 \mathrm{H}$. The depth of penetration, mechanical and metallurgical characteristics of the weldments were analysed.

\section{EXPERIMENTAL PROCEDURE}

Incoloy $800 \mathrm{H}$ of dimension $100 \times 75 \times 4 \mathrm{~mm}$ was chosen as the base material. The chemical composition of Incoloy $800 \mathrm{H}$ is shown in Table 1. Five different fluxes $\left(\mathrm{TiO}_{2}, \mathrm{Cr}_{2} \mathrm{O}_{3}, \mathrm{MoO}_{3}\right.$, $\mathrm{V}_{2} \mathrm{O}_{5}$, and $\mathrm{Al}_{2} \mathrm{O}_{3}$ ) were mixed with acetone in the ratio of 1:6.5 separately to form a paste. $\mathrm{A}$ thin layer of flux coating was applied on the region where the weld was to be made. Prior to the application of flux, the base material was cleaned with emery sheets and acetone to keep the surface away from contaminants. A-TIG welding and autogeneous TIG welding were performed using Lincoln TIG welding machine and the process parameters used to complete the weld are shown in Table 2. After welding the weldments were cut in the cross section of the weldments using a wire cut EDM machine to analyse the effect of different flux on the mechanical and metallurgical characteristics of the weldments. The schematic representation of coupons obtained from the A-TIG weldments for mechanical and metallurgical characterization is shown in fig. 1. The cross sectioned weldments were polished with different grade of emery sheets followed by alumina and diamond polishing to get mirror finish. The etchant with the combination of $15 \mathrm{ml} \mathrm{HCL}+10 \mathrm{ml} \mathrm{HNO}_{3}+10 \mathrm{ml} \mathrm{CH} \mathrm{CHOH}_{3}$ was used to reveal the macro and microstructure of the welded joints. The depth and width of 
the weld bead were measured using IMAGE-J software. The SEM with EDS analysis was made using Carl Zeiss $\sigma$ version machine in high vacuum mode. The hardness was measured using Vickers micro hardness tester, loaded with $500 \mathrm{~g}$ for a dwell time of $15 \mathrm{~s}$ transverse cross-section of the weldments at different locations.

Table 1. Chemical elements of Incoloy $800 \mathrm{H}$

\begin{tabular}{c|c|c|c|c|c|c|c|c|c}
\hline $\mathrm{C}$ & $\mathrm{Mn}$ & $\mathrm{S}$ & $\mathrm{Si}$ & $\mathrm{Cu}$ & $\mathrm{Cr}$ & $\mathrm{Fe}$ & $\mathrm{Al}$ & $\mathrm{Ti}$ & $\mathrm{Ni}$ \\
\hline 0.065 & 0.688 & $<0.010$ & 0.094 & 0.091 & 20.79 & 46.60 & 0.277 & 0.280 & 30.65 \\
\hline
\end{tabular}

Table 2. Welding parameters

\begin{tabular}{l|l|l}
\hline Parameters & Values & Units \\
\hline Welding Current & 100 & Amps \\
Arc Length & 2 & $\mathrm{~mm}$ \\
Shielding Gas & Argon & $99.999 \%$ pure \\
shielding gas flow rate & 15 & $1 \mathrm{pm}$ \\
& & $\emptyset$ \\
& & \\
Electrode Diameter & 2.4 & \\
Welding Speed & 50 & $\mathrm{~mm} / \mathrm{min}$ \\
Power Polarity & DCEN & \\
Electrode type & $2 \%$-wt ThO $\mathrm{Th}_{2}$ thoriated tungsten. & \\
\hline
\end{tabular}

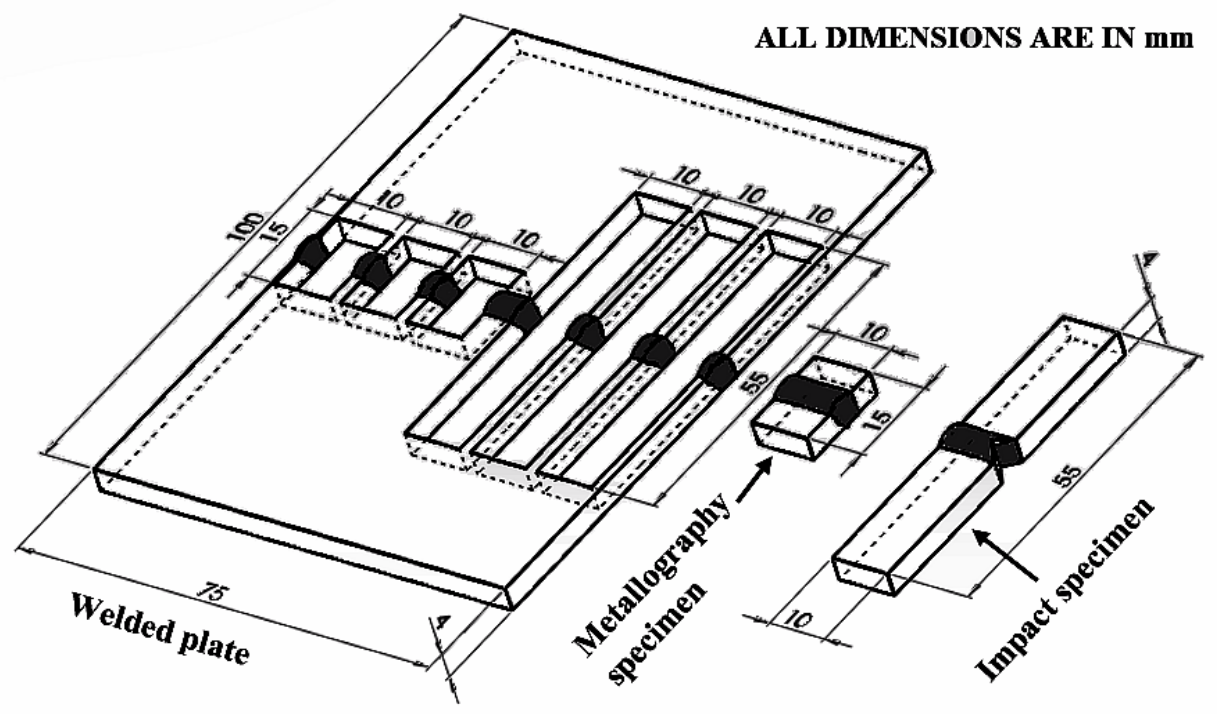

Fig. 1. Schematic representation of coupons obtained from the A-TIG weldments for metallurgical and mechanical characterization studies 


\section{RESULT AND DISCUSSION}

\section{Macrostructure of the weld region}

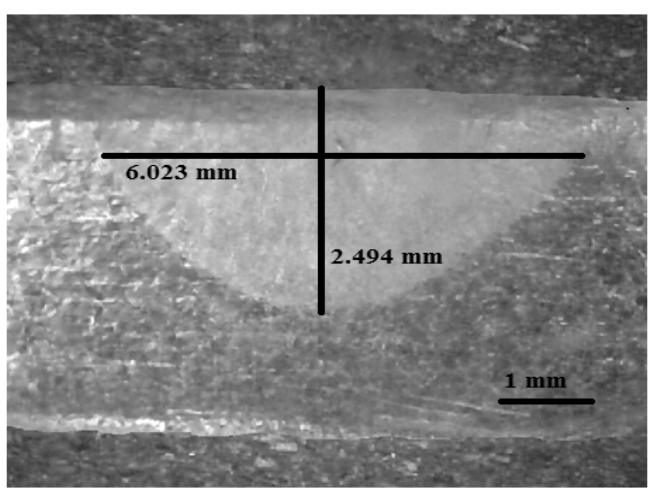

a)Autogenous TIG weld

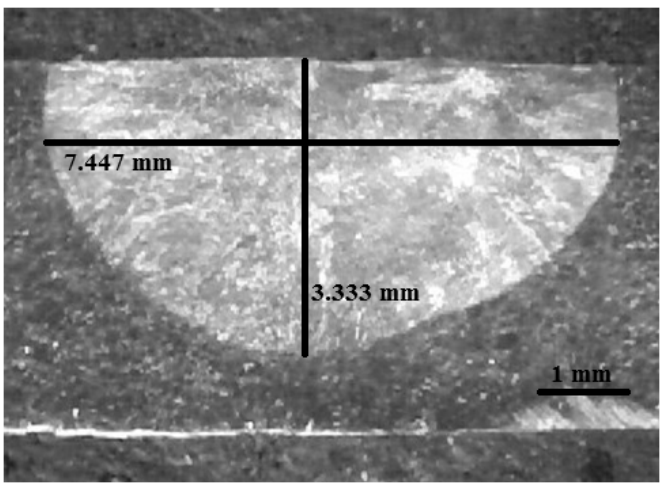

d) A-TIG weld with $\mathrm{Cr}_{2} \mathrm{O}_{3}$

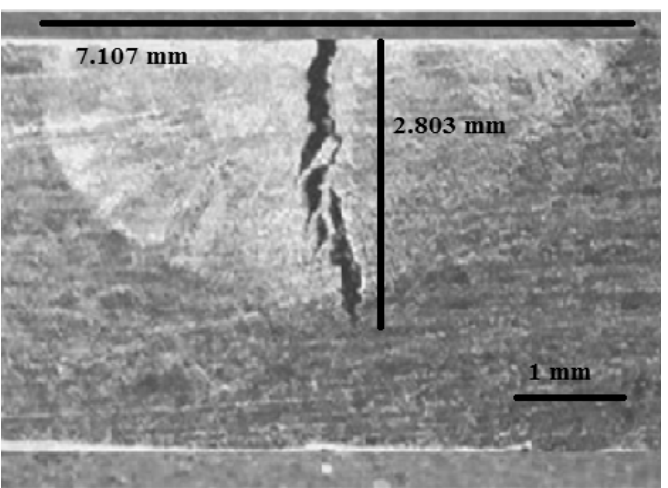

f) A-TIG weld with $\mathrm{MoO}_{3}$

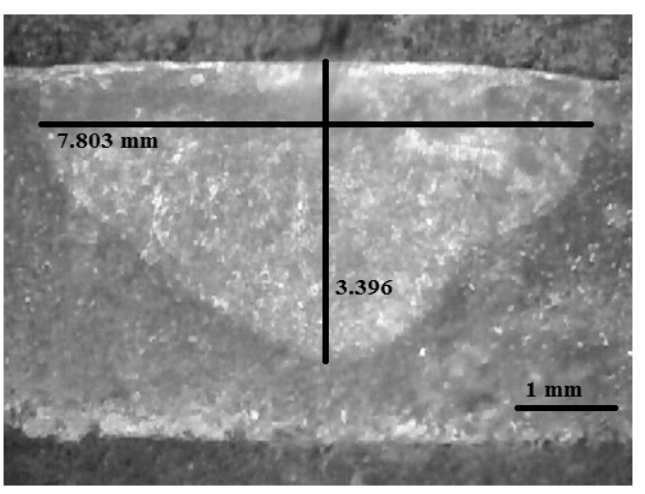

b) A-TIG weld with $\mathrm{V}_{2} \mathrm{O}_{5}$

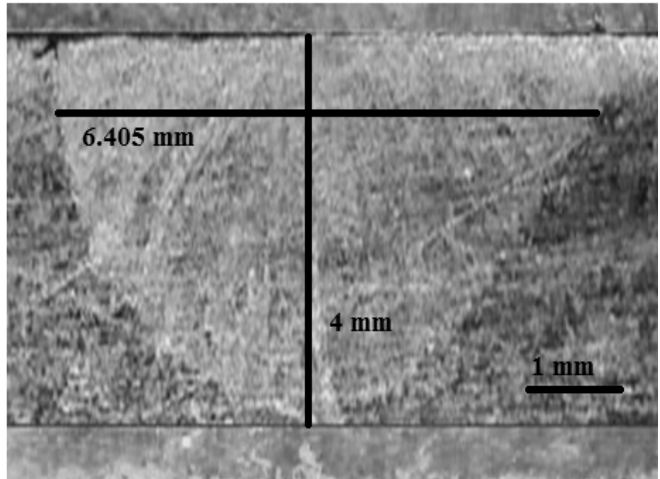

e) A-TIG weld with $\mathrm{TiO}_{2}$

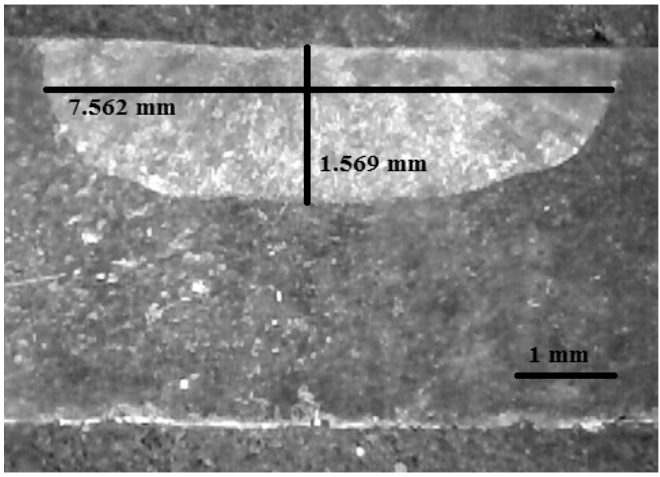

g) A-TIG weld with $\mathrm{Al}_{2} \mathrm{O}_{3}$

Fig. 2. Macrostructure of the weldments

Fig. 2 shows the macrostructure of the autogeneous TIG and A-TIG weldments. From the figure 2 (a) it can be seen that the autogeneous TIG gave a weld depth of $2.494 \mathrm{~mm}$. Compared to the autogeneous weld zone depth, the use of $\mathrm{TiO}_{2}$ flux (fig. 2 (e)) gave a full 
depth penetration and $\mathrm{V}_{2} \mathrm{O}_{5}, \mathrm{Cr}_{2} \mathrm{O}_{3}$ flux (fig. $2(\mathrm{~b} \& \mathrm{~d})$ ) gave a deeper penetration. The use of $\mathrm{Al}_{2} \mathrm{O}_{3}$ flux (fig. $2(\mathrm{~g})$ ) gave a lesser depth of penetration. Most likely the increased depth in penetration was due to the reversed Marangoni convection which relates the penetration depth to the fluid flow direction. The molten fluid flow direction is determined by the temperature co-efficient of surface tension. In TIG welding the convection movements were centrifugal and surface tension gradient in negative led to shallow penetration. The addition of activating flux improved the oxygen content which induced an inversion of the convection currents changing the sign of the surface tension gradient from negative to positive and the resulting convection current movements changed to centripetal. Hence the depth of penetration increased [12]. Also the depth of penetration depended upon the interaction between base material composition and the flux, the type of flux used and the process parameters involved during the welding [9]. The use of $\mathrm{MoO}_{3}$ flux led to hot cracking issue in Incoloy $800 \mathrm{H}$ whereas this defect was not reported in materials such as duplex stainless steel, Inconel 718 and $316 \mathrm{~L}$ austenitic stainless steel [13-16]. Hot cracking is a welding defect that occurs with

temperature higher than $1200^{\circ} \mathrm{C}$ and it is due to the presence of impurities with lower melting

than the base metal. The cooling is greater on the weld region and it is from there that grain grows forwards the centre of the weld which is the last to become solid. Since almost all alloys, solidify over a range of temperature, the first metal to solidify will have higher melting point and the last will have the lowest melting point. As a consequence of this, the lowest melting point composition is pushed ahead of the solidifying dendrite until it gets trapped between the adjacent dendrites, along the grain boundaries. If the difference in melting point between the lowest melting point constraint and rest of the bulk material is sufficiently great, the liquid films by the grain boundaries will be separated as cools and contracts leading to hot cracking. Some theories suggest that hot cracking is dependent on the metallurgical and mechanical factors that are supposed to be independent of each other [17-18]. Further studies have also shown that cracking could also be initiated at the early stage of solidification [19].

\section{Microstructure of the base material}

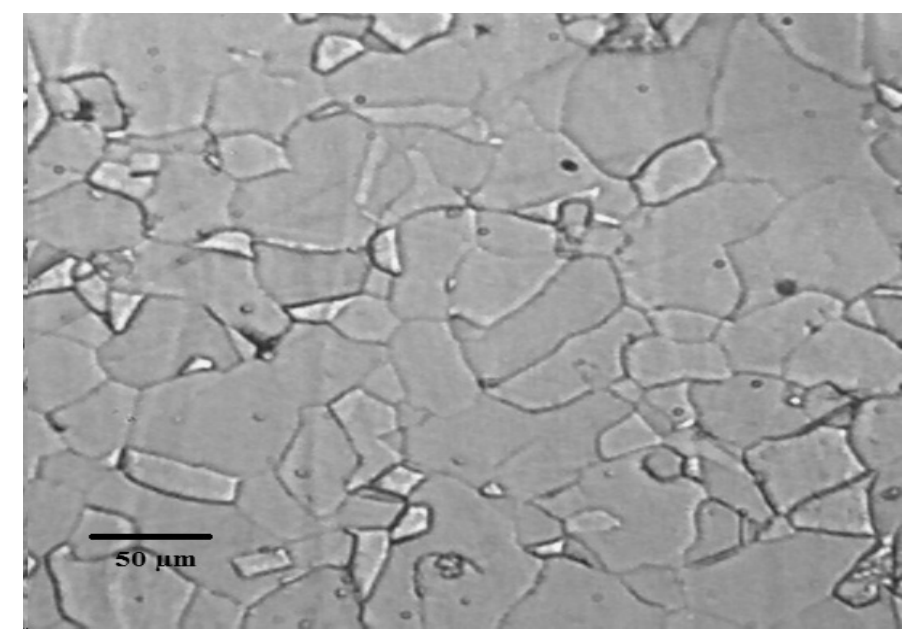

Fig. 3. Microstructure of the base material 
Fig. 3 shows the microstructure of the base material Incoloy $800 \mathrm{H}$ as received in mill and annealed condition which was solution treated at a temperature of approximately $1150^{\circ} \mathrm{C}$ to promote grain growth and dissolution of carbides. This left some of the carbon available for precipitation during service. The microstructure consisted of a solid solution matrix in which some grains were delineated by intergranular carbonitrides and by twining lines.

\section{Microstructure of the weld region}

Fig. 4 shows the microstructure of the weld of autogeneous TIG weld and A-TIG welds with the use of different activating fluxes.

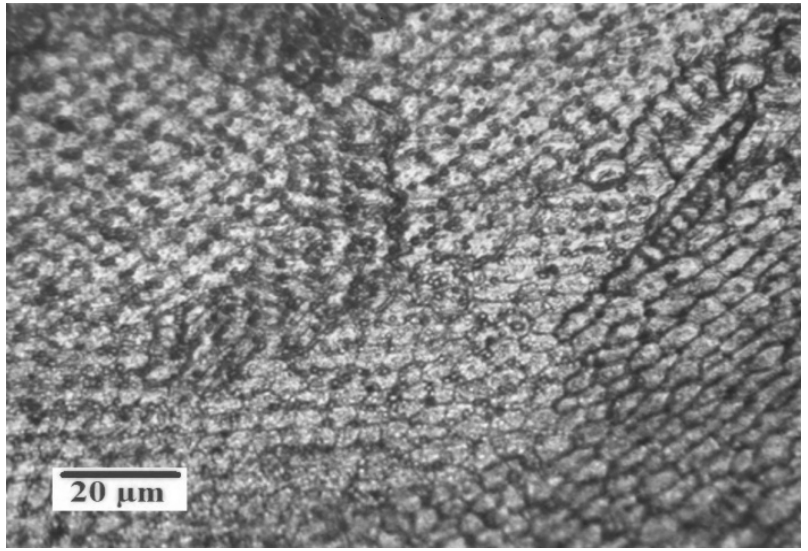

a) Autogenous TIG weld

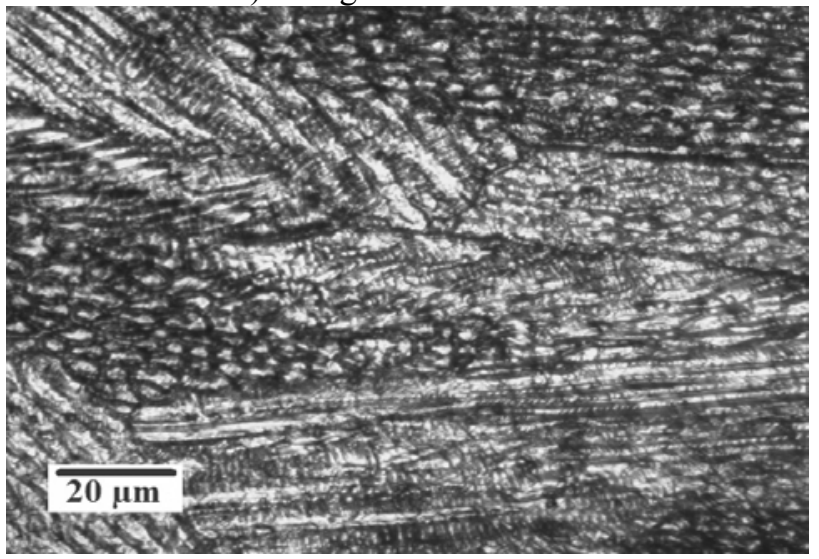

c) A-TIG weld with $\mathrm{Cr}_{2} \mathrm{O}_{3}$

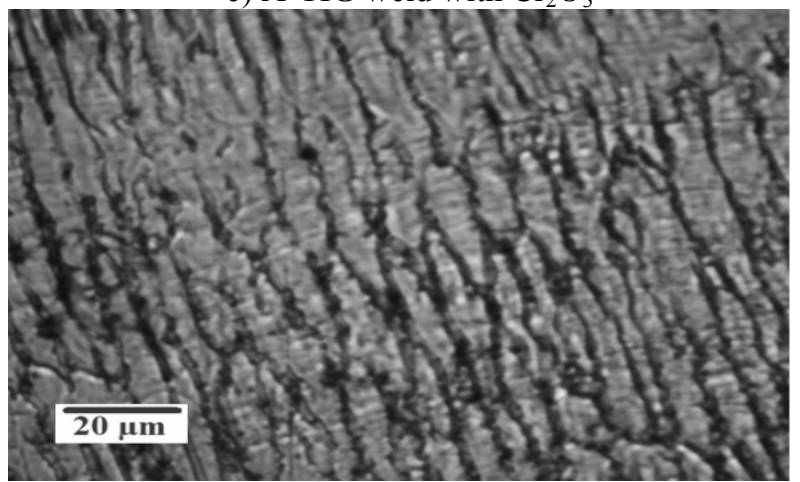

e) A-TIG weld with $\mathrm{MoO}_{3}$

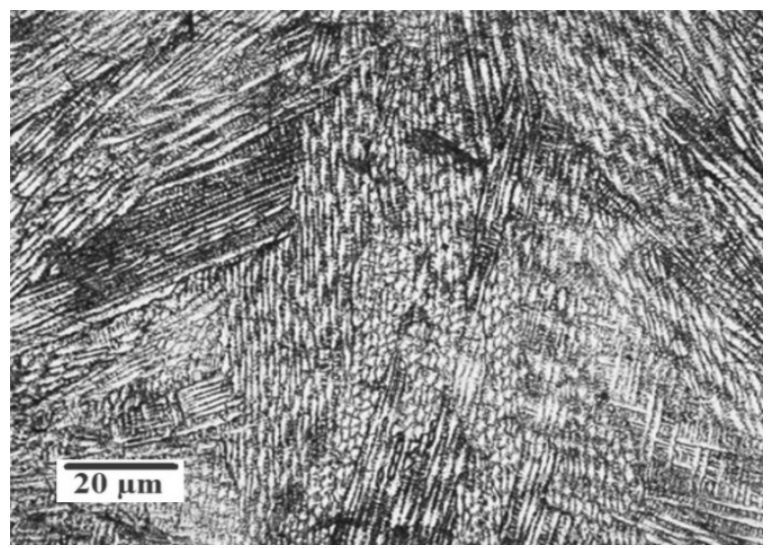

b) A-TIG weld with $\mathrm{V}_{2} \mathrm{O}_{5}$

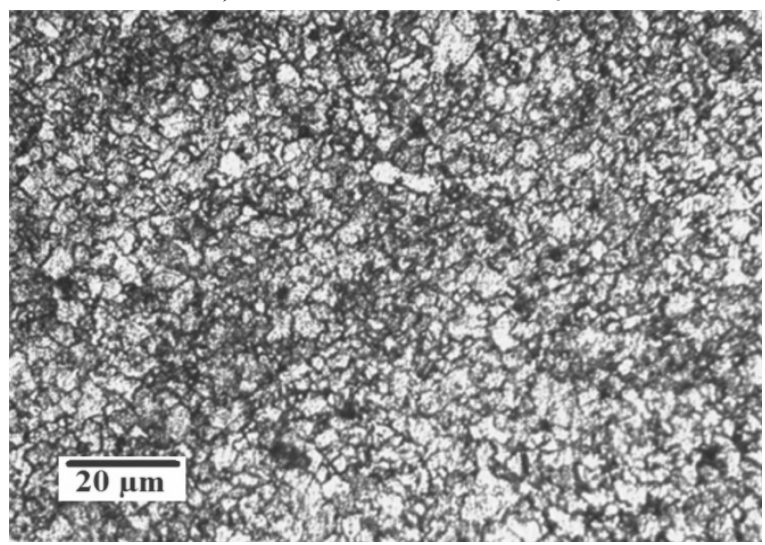

d) A-TIG weld with $\mathrm{TiO}_{2}$

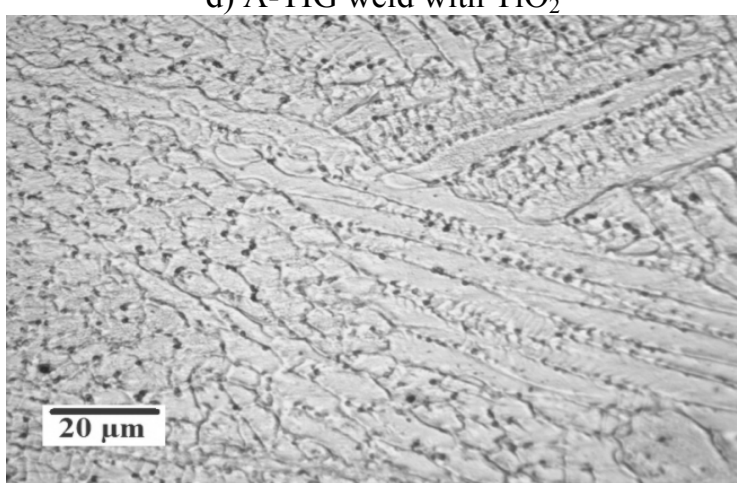

f) A-TIG weld with $\mathrm{Al}_{2} \mathrm{O}_{3}$

Fig. 4. Microstructure of the autogeneous TIG weld and A-TIG 
It can be seen from the figures that each flux gave different microstructure in the weld region. The autogeneous weld region exhibited equiaxed grain structure and $\mathrm{TiO}_{2}$ flux gave a much finer grain equiaxed grain structure as compared with the autogeneous welds. The equiaxed grain structure is most preferred structure because it can exhibit higher strength than the other solidification structures. The use of $\mathrm{Cr}_{2} \mathrm{O}_{3}$ and $\mathrm{V}_{2} \mathrm{O}_{5}$ flux produced a combination of equiaxed and columnar structure throughout the weld region but the $\mathrm{V}_{2} \mathrm{O}_{5}$ flux exhibited much finer grains. The advantage of combination that fine grain sizes confer on metal structures is unique; as it increases strength, toughness and fatigue life [20-21].The $\mathrm{Al}_{2} \mathrm{O}_{3}$ and $\mathrm{MoO}_{3}$ flux led to the formation of coarser dendritic structures which was not preferred in most welding application, as dendrites were more prone to cracking. It is also seen that the use of $\mathrm{MoO}_{3}$ flux caused solidification cracking in the weld metal. There are certain stages, there are certain particular patterns or the modes through which solidification takes place and these modes basically, dictate the structure of the weld, which is developed after the solidification. And these modes of the solidification depend upon the composition of the weld metal and the cooling conditions experienced during the welding, and this means that, the solidification can take place in different modes like planar, cellular, dendritic and the equiaxed. The actual temperature gradient $(\mathrm{G})$ and growth rate $(\mathrm{R})$ have a major influence on the solidification mode. A combination of high $\mathrm{G}$ and low $\mathrm{R}$ results in planar solidification, $\mathrm{A}$ combination of low $\mathrm{G}$ and high $\mathrm{R}$ results in equiaxed solidification and the combination of intermediate values of $\mathrm{G}$ and $\mathrm{R}$ results in the cellular and dendrite mode of solidification [22].

$X R D$ analysis of the weld region

Fig. 5 Presents the XRD results of the weld region, welded with the application of different flux.

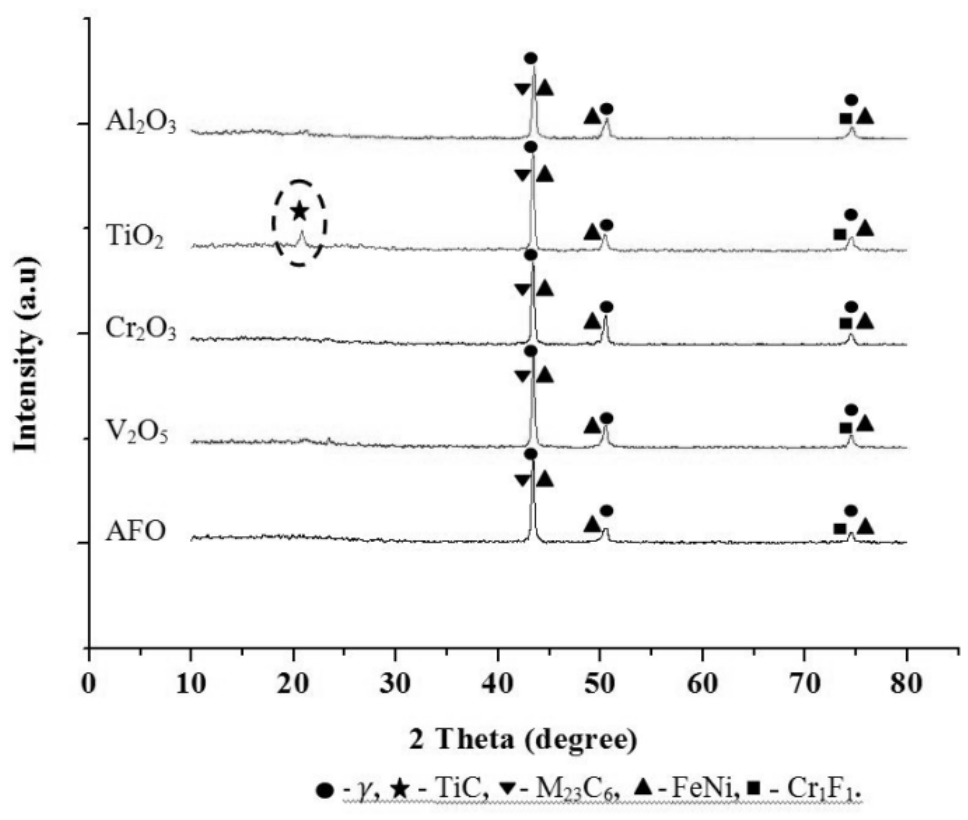

Fig. 5. XRD results of the weld region 
The XRD peaks were searched using X'Pert High Score Plus software to find the possible phase transformation during welding. The phase identified was the austenite phase $(\gamma)$ as nickel is a stabilizer. Iron nickel carbides $\left(\mathrm{M}_{23} \mathrm{C}_{6}\right)$ and chromium nickel carbides were formed for all the weldments. The $\mathrm{M}_{23} \mathrm{C}_{6}$ carbides form near the grain boundaries. When the grain boundary is much finer, the $\mathrm{M}_{23} \mathrm{C}_{6}$ will be beneficial to the fatigue property of the alloy, strengthening the grain boundary and preventing the migration of grain boundaries during deformation [23]. The weld using $\mathrm{TiO}_{2}$ flux alone showed the formation titanium carbides (TiC). These carbides do not dissolve in elevated temperature environment and the grain boundaries can thus enhance the fracture resistance of the material [24].

\section{Fractography analysis}

The Fig. 6 shows the impact tested specimen of the $\mathrm{TiO}_{2}$ welds which gave full depth of penetration.

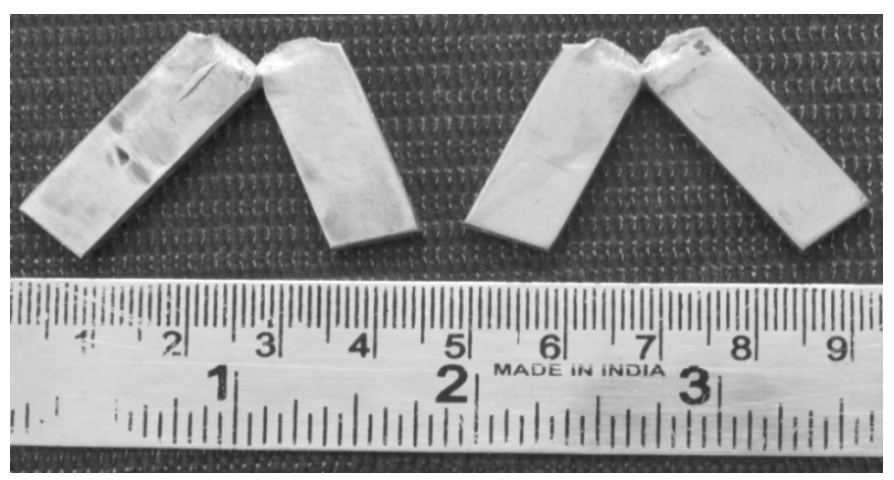

Fig. 6. Photograph of the Impact tested specimen

Two samples were prepared and tested by making a V-notch at the centre of the weld. The toughness obtained was $72 \mathrm{~J}$ and $75 \mathrm{~J}$ respectively and it was higher than the TIG welded joints $(60 \mathrm{~J})$ as reported by Arun Kumar et al. [25]. Further the fractured surface was analysed through SEM at two different locations and is shown in Fig. 7. The figure clearly depicts mostly voids and dimples which corresponded to the ductile mode of fracture. 

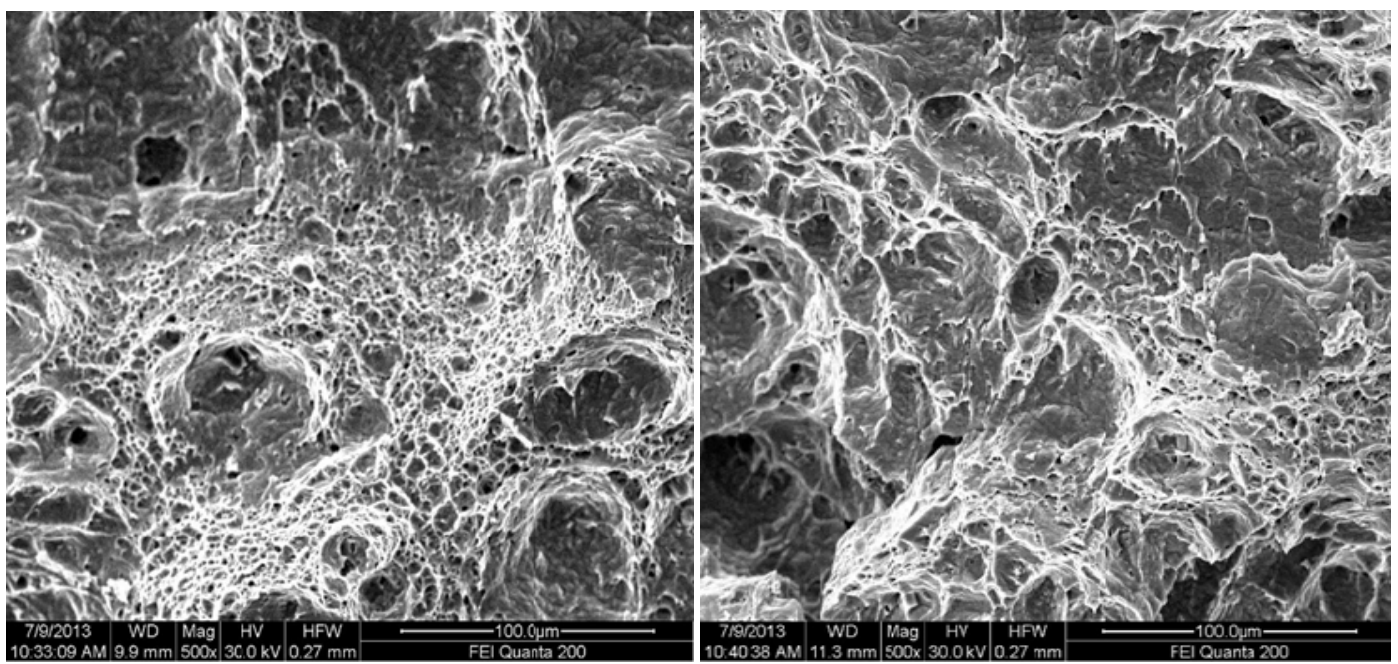

Fig. 7. Fractography of the impact tested specimen

\section{Hardness}

The fig. 8 shows the hardness profile of the welds.

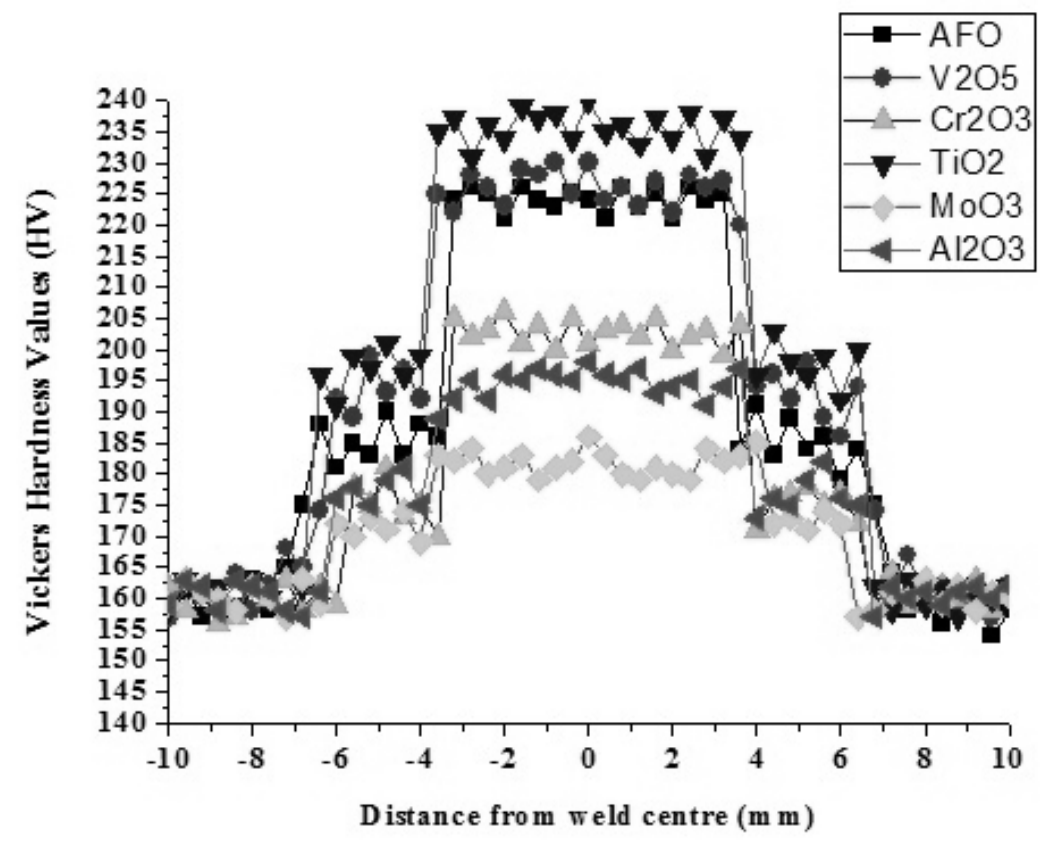

Fig. 8. Hardness profile of the welds

The $\mathrm{TiO}_{2}$ weld and $\mathrm{V}_{2} \mathrm{O}_{5}$ welds exhibited higher hardness $(240 \& 230 \mathrm{HV})$ than the autogeneous welds $(226 \mathrm{HV})$. This may be due to fine grain size and formation of the titanium carbides in the weld region of the $\mathrm{TiO}_{2}$ welds. The low hardness of the other welds as compared to the autogeneous weld may be due to coarser grain structure obtained in the weld region. 


\section{Corrosion Analysis}

The potentiodynamic polarization test was carried for the base material and $\mathrm{TiO}_{2}$ weldments. Two tests were carried out for the weld region to check the repeatability of the results. 1 mole of $\mathrm{NaCl}$ mixed in one litre of distilled water was used as the electrolytic solution. 1 hour of stabilizing time was given before each polarisation scan. The local polarization curve was plotted from $-1 \mathrm{~V}$ to $1 \mathrm{~V}$ at a scan rate of $0.5 \mathrm{mV} / \mathrm{s}$. The fig. 9 shows the polarization curves taken for the base material and two weldments. From the Figure it can be seen that the current density was less for the weldments which means that the loss of electrons was less thus providing better corrosion resistance compared to the base material. This may be due to the fine grain size, the formation of iron chromium carbides and titanium carbides in the weld region. Also both the weld samples exhibited similar polarization curves.

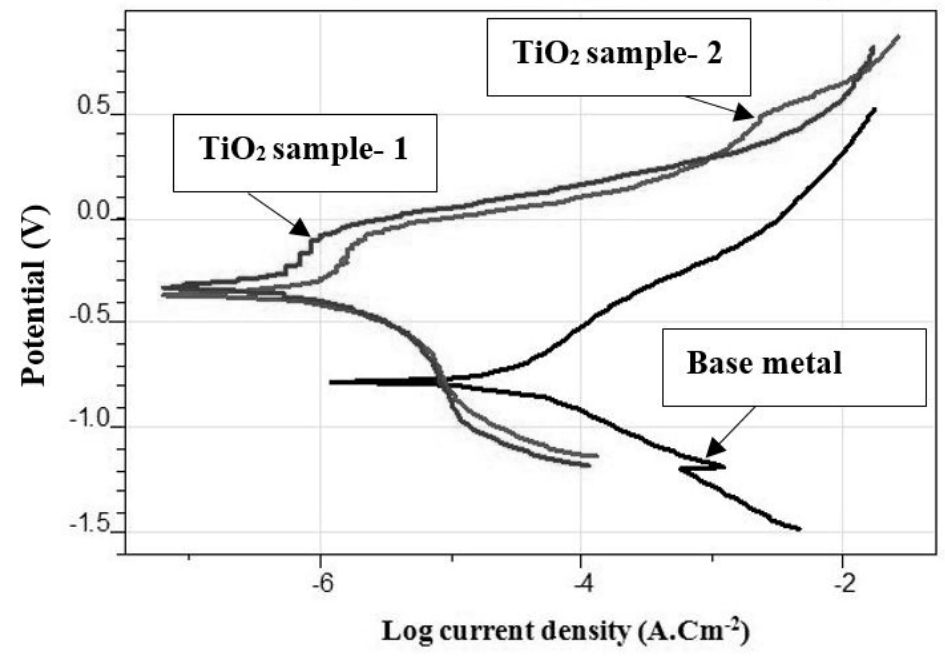

Fig. 9. Tafel plot

\section{CONCLUSIONS}

The A-TIG welding was carried on Incoloy $800 \mathrm{H}$ with different flux $\left(\mathrm{V}_{2} \mathrm{O}_{5}, \mathrm{TiO}_{2}, \mathrm{Cr}_{2} \mathrm{O}_{3}\right.$, $\mathrm{MoO}_{3}$ and $\mathrm{Al}_{2} \mathrm{O}_{3}$ ). Full depth of penetration was observed in A-TIG welding process for 4 mm thick Incoloy $800 \mathrm{H}$ plates by using $\mathrm{TiO}_{2}$ as an activating flux. An increase in penetration of $133 \%$ was obtained for $\mathrm{V}_{2} \mathrm{O}_{5}$ and $\mathrm{Cr}_{2} \mathrm{O}_{3}$ flux as compared to the autogeneous TIG weld. The reversed Marangoni convection was the cause for the increased depth of penetration. The use of $\mathrm{MoO}_{3}$ caused solidification cracking in the weldment. The use of $\mathrm{TiO}_{2}$ and $\mathrm{V}_{2} \mathrm{O}_{5}$ flux showed finer grain size and higher hardness in the weld region as compared to other welds. The XRD peaks revealed the formation of titanium carbides in the weld region of $\mathrm{TiO}_{2}$ welds which would give resistance to fracture. The toughness of $\mathrm{TiO}_{2}$ weldments was more when compared to the TIG welded Incoloy $800 \mathrm{HT}$ joints. The $\mathrm{TiO}_{2}$ weldments had improved corrosion resistance as compared to the autogeneous TIG welded joints. 


\section{REFERENCES}

1. http://www.specialmetals.com/assets/documents/alloys/incoloy/incoloy-alloy-800.pdf

2. Paulo J. Modenesi., EustaÂquio R. ApolinaÂrio., Iaci M. Pereira., TIG welding with singlecomponent fluxes. Journal of Materials Processing Technology, 99 (2000), 260-265.

3. Kuang-Hung Tseng, Chih-Yu Hsu. Performance of activated TIG process in austenitic stainless steel welds. Journal of Materials Processing Technology, 211 (2011), 503-512.

4. Xu Y.L., Dong Z.B., Wei Y.H., Yang C.L., Marangoni convection and weld shape variation in ATIG welding process. Theoretical and Applied Fracture Mechanics, 48 (2007), 178-186.

5. Chunli YANG., Sanbao LIN., Fengyao LIU., Lin WU., Qingtao ZHANG., Research on the Mechanism of Penetration Increase by Flux in A-TIG Welding. Journal of Materials Science \& Technology, 19(1) (2003), 225-227.

6. Sakthivel T., Vasudevan M., Laha K., Parameswaran P., Chandravathi K.S., Mathew M.D., Bhaduri A.K., Comparison of creep rupture behaviour of type $316 \mathrm{~L}(\mathrm{~N})$ austenitic stainless steel joints welded by TIG and activated TIG welding processes. Materials Science and Engineering: A, 528 (2011), 6971-6980.

7. Devendranath Ramkumar K., Jelli Lakshmi Narasimha Varma., Gangineni Chaitanya., Ayush Choudhary., Arivazhagan N., Narayanan S., Effect of autogeneous GTA welding with and without flux addition on the microstructure and mechanical properties of AISI $904 \mathrm{~L}$ joints. Materials Science and Engineering: A, 636 (2015), 1-9.

8. Devendranath Ramkumar K., Monoj Kumar B., Gokul Krishnan M., Sidarth Dev., Aman Jayesh Bhalodi., Arivazhagan N., Narayanan S., Studies on the weldability, microstructure and mechanical properties of activated flux TIG weldments of Inconel 718. Materials Science and Engineering: A, 639 (2015), 234-244.

9. Shyu S.W., Huang HY., Tseng K H., Chou C.P., Study of the Performance of Stainless Steel ATIG Welds. Journal of Materials Engineering and Performance, 17 (2008), 193-201.

10. Hsuan-Liang Lin., Tong-Min Wu., Ching-Min Cheng., Effects of Flux Precoating and Process Parameter on Welding Performance of Inconel 718 Alloy TIG Welds. Journal of Materials Engineering and Performance, 23 (2014), 125-132.

11. Sayiram G., Arivazhagan N., Microstructural characterization of dissimilar welds between Incoloy $800 \mathrm{H}$ and 321 Austenitic Stainless Steel. Materials Characterization, 102 (2015), 180188.

12. Rui-Hua ZHANG., Ji-Luan PAN., Seiji KATAYAMA., The mechanism of penetration increase in A-TIG welding. Frontiers of Materials Science, 5(2) (2011), 109-118.

13. Tsann-Shyi Chern., Kuang-Hung Tseng., Hsien-Lung Tsai., Study of the characteristics of duplex stainless steel activated tungsten inert gas welds. Materials and Design, 32 (2011), 255-263.

14. Kuang-Hung Tseng., Chih-Yu Hsu., Performance of activated TIG process in austenitic stainless steel welds. Journal of Materials Processing Technology, 211 (2011), 503-512.

15. Hsuan-Liang Lin., Tong-Min Wu., Effects of Activating Flux on Weld Bead Geometry of Inconel 718 Alloy TIG Welds. Materials and Manufacturing Processes, 27 (2012), 1457-1461.

16. Kuang-Hung Tseng., Development and application of oxide-based flux powder for tungsten inert gas welding of austenitic stainless steels. Powder Technology, 233 (2013), 72-79.

17. Fink C., Keil D., Zinke M., Evaluation of hot cracking susceptibility of nickel-based alloys by the pvr test. Welding in the World, 56(7) (2012), 37-43. 
18. Borland J C., Younger R N., Some aspects of cracking in welded $\mathrm{Cr}-\mathrm{Ni}$ austenitic steels. British Welding Journal, 7 (1960), 22-59.

19. Matsuda F., Nakagawa H., Sorada K., Dynamic observation of solidification and solidification cracking during welding with optical microscope. Transactions of the Japan Welding Research Institutetute, 11 (1982), 67-77.

20. Hall EO., The Deformation and Aging of Mild steel. Proceedings of the Physical Society, 64B (1951), 747-753.

21. Garstone J., Johnson FA., Impact Properties of Mild Steel Weld Metals. British Welding Journal, 10(5) (1963), 224.

22. Sindo Kou.: Welding Metallurgy. Second Edition. John Wiley \& Sons, Incorporated, Hoboken, NJ, USA, 2003.

23. He L Z., Zheng Q., Sun X F., Hou GC., Guan H R., Hu ZQ., M23C6 precipitation behavior in a Ni-base superalloy M963. Journal of Materials Science, 40 (11) (2005), 2959-2964.

24. Sireesha M., Shankar V., Shaju K Albert., Sundaresan S., Microstructural features of dissimilar welds between 316LN austenitic stainless steel and alloy 800. Materials Science and Engineering: A, 292 (1) (2000), 74-82.

25. Arun Kumar Srirangan., Sathiya Paulraj., Multi-response optimization of process parameters for TIG welding of Incoloy $800 \mathrm{HT}$ by Taguchi grey relational analysis. Engineering Science and Technology, an International Journal. doi:10.1016/j.jestch.2015.10.003. 